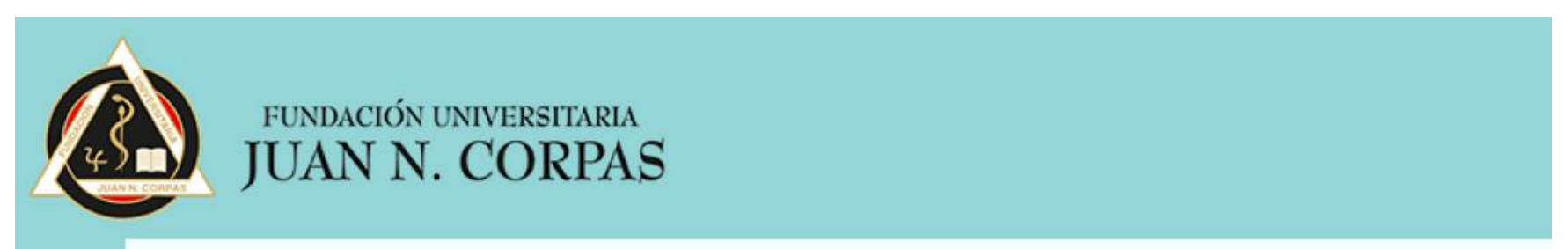

\title{
HILANDO EL CAMBIO
}

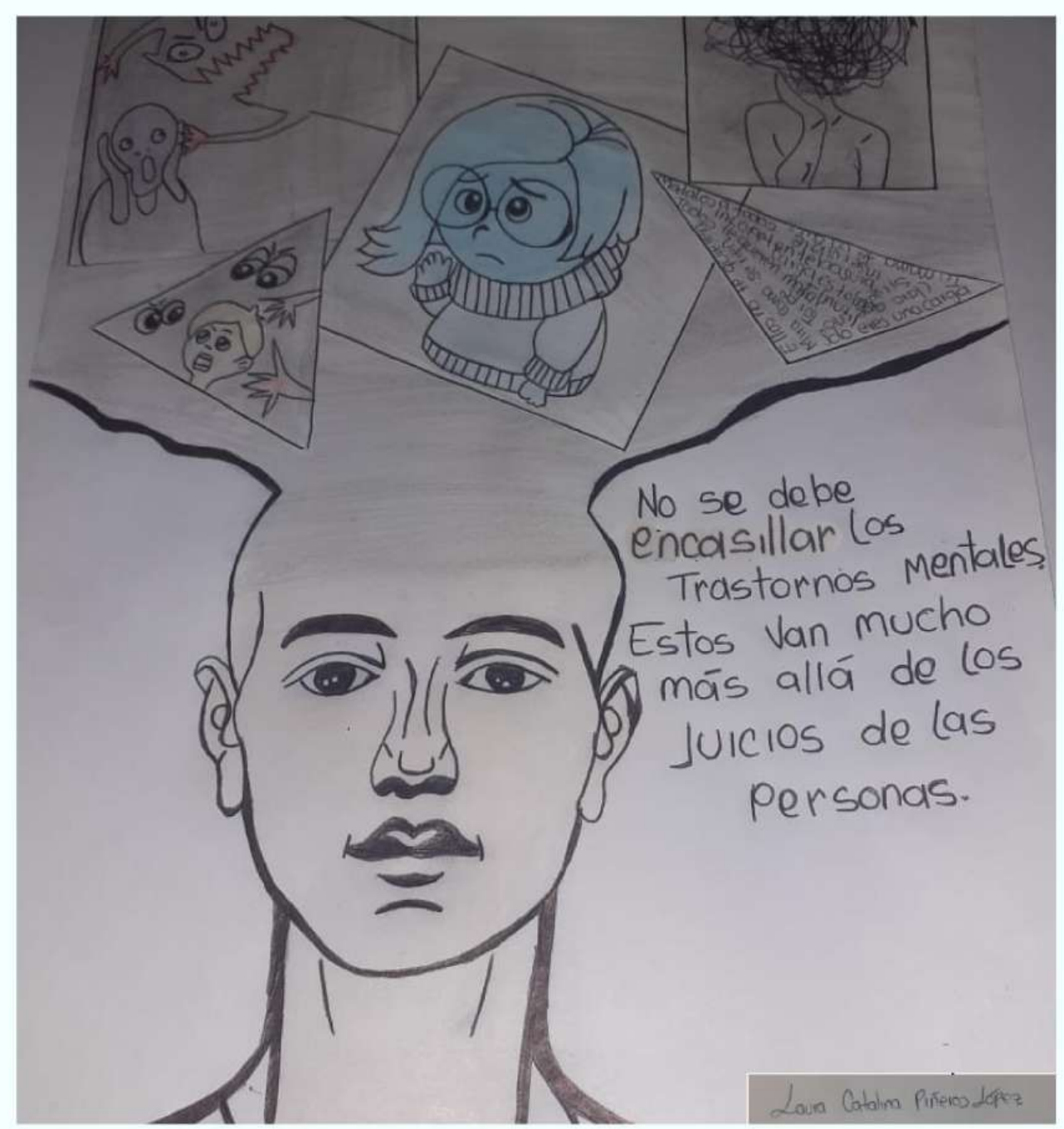

Proyecto final Cuidados de Enfermería V: paciente con alteraciones mentales

Enfermería - Semestre VIII

$2021-02$ 


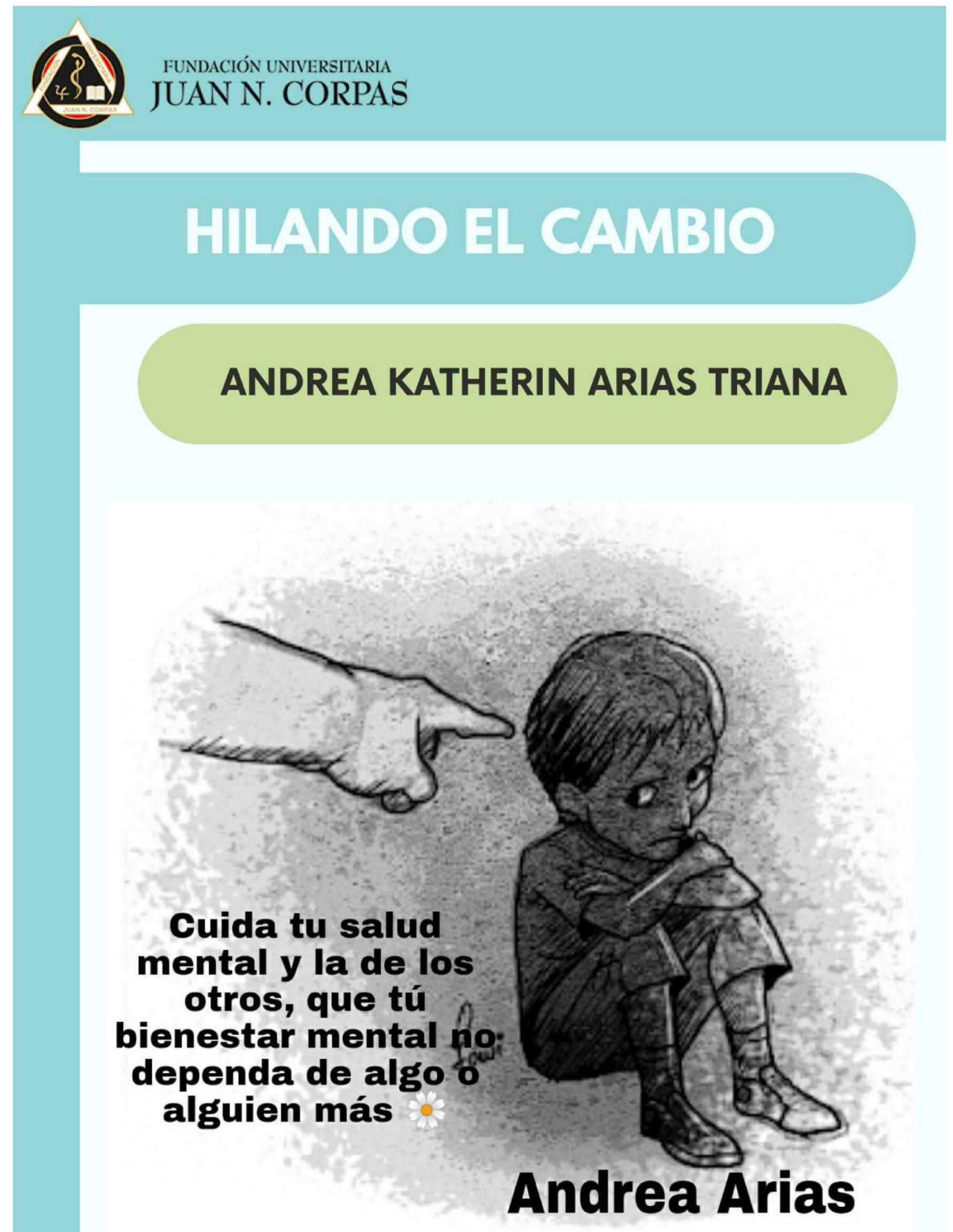




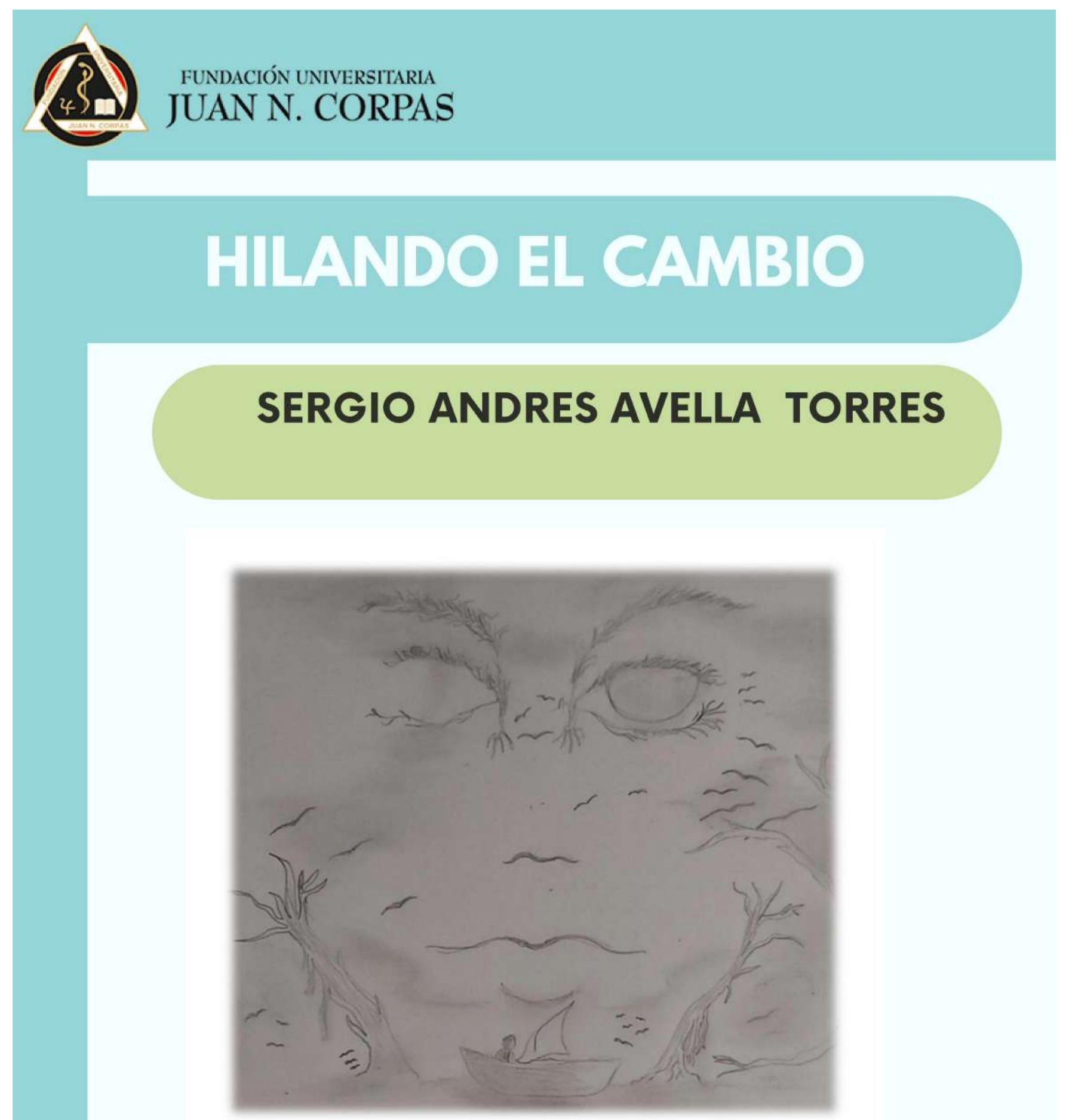

Las personas con trastornos mentales tienen la capacidad de soñar e imaginar mundos diferentes sí, pero ¿quién dijo que todos somos iguales? 


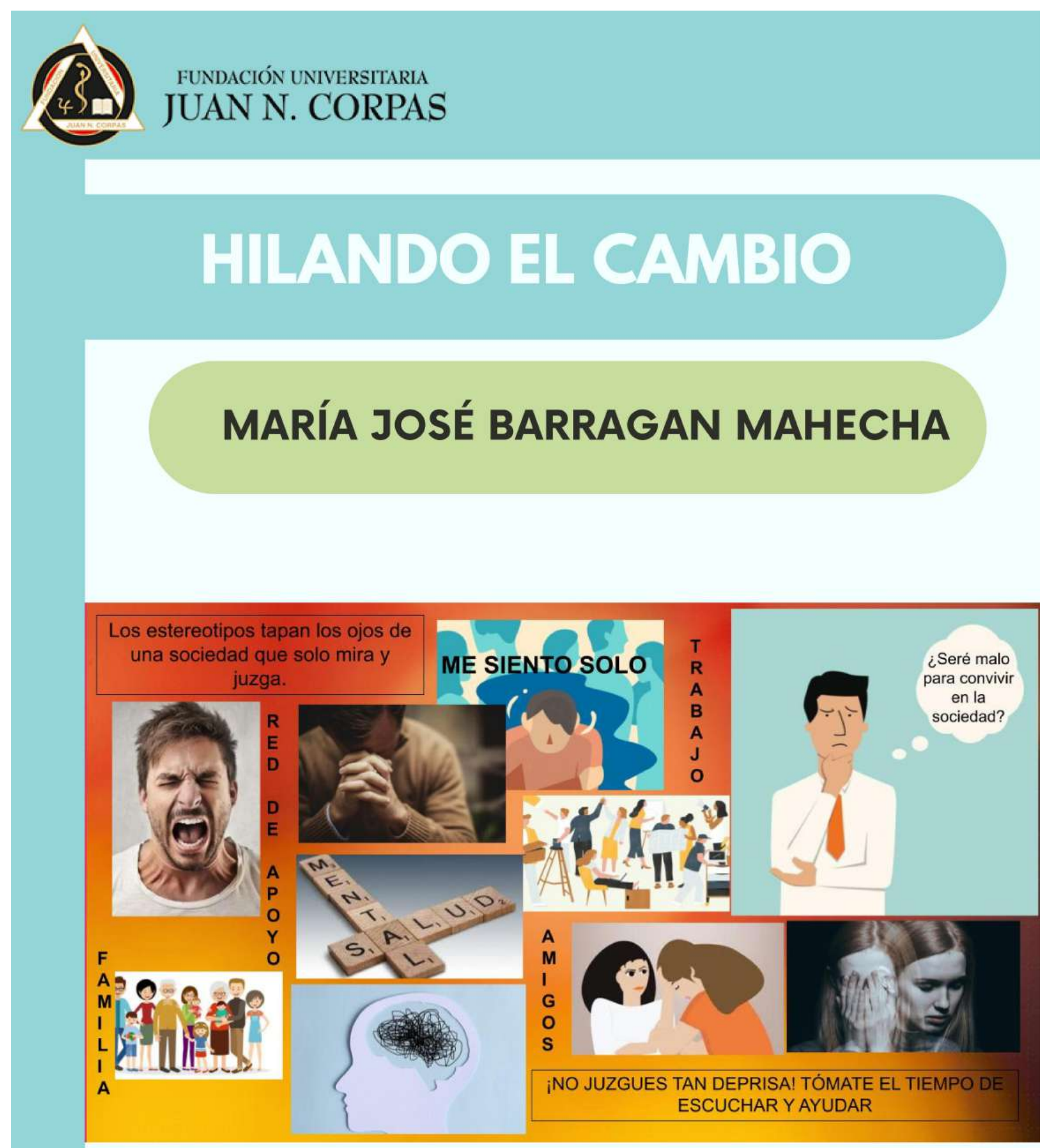




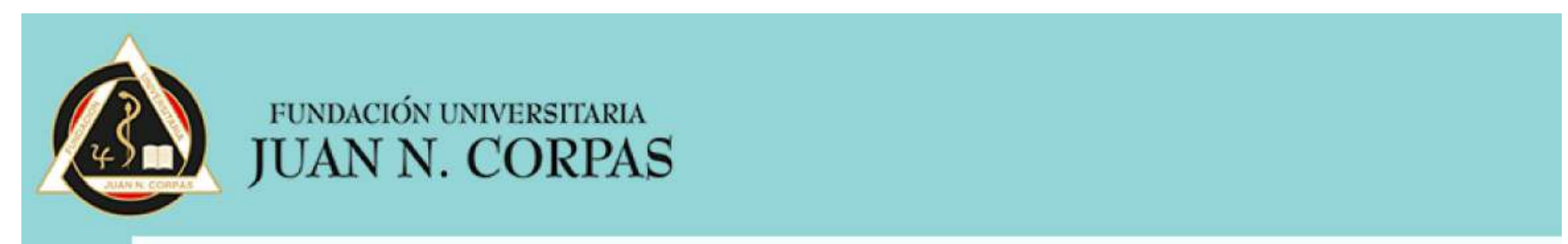

\section{HILANDO EL CAMBIO}

\section{DANIEL BECERRA PABÓN}

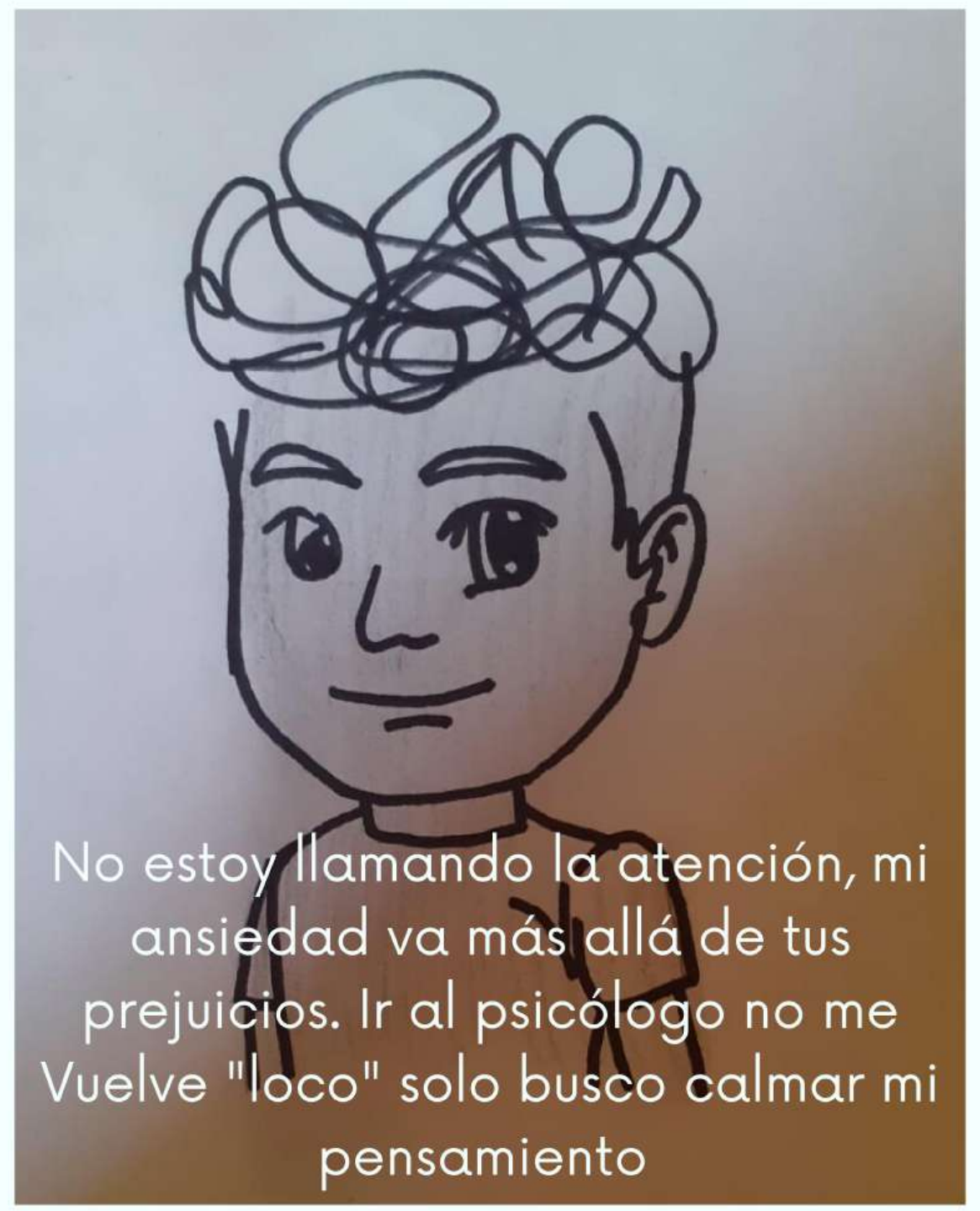




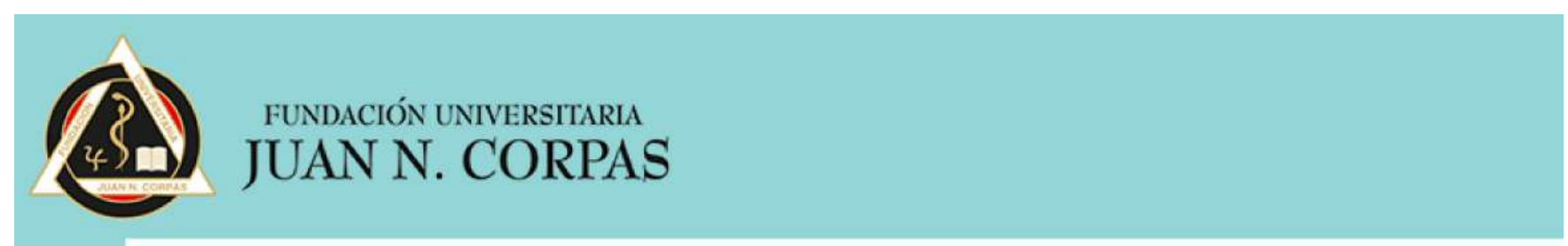

\section{HILANDO EL CAMBIO}

\section{YERLY JHOMARA BLANCO RINCÓN}

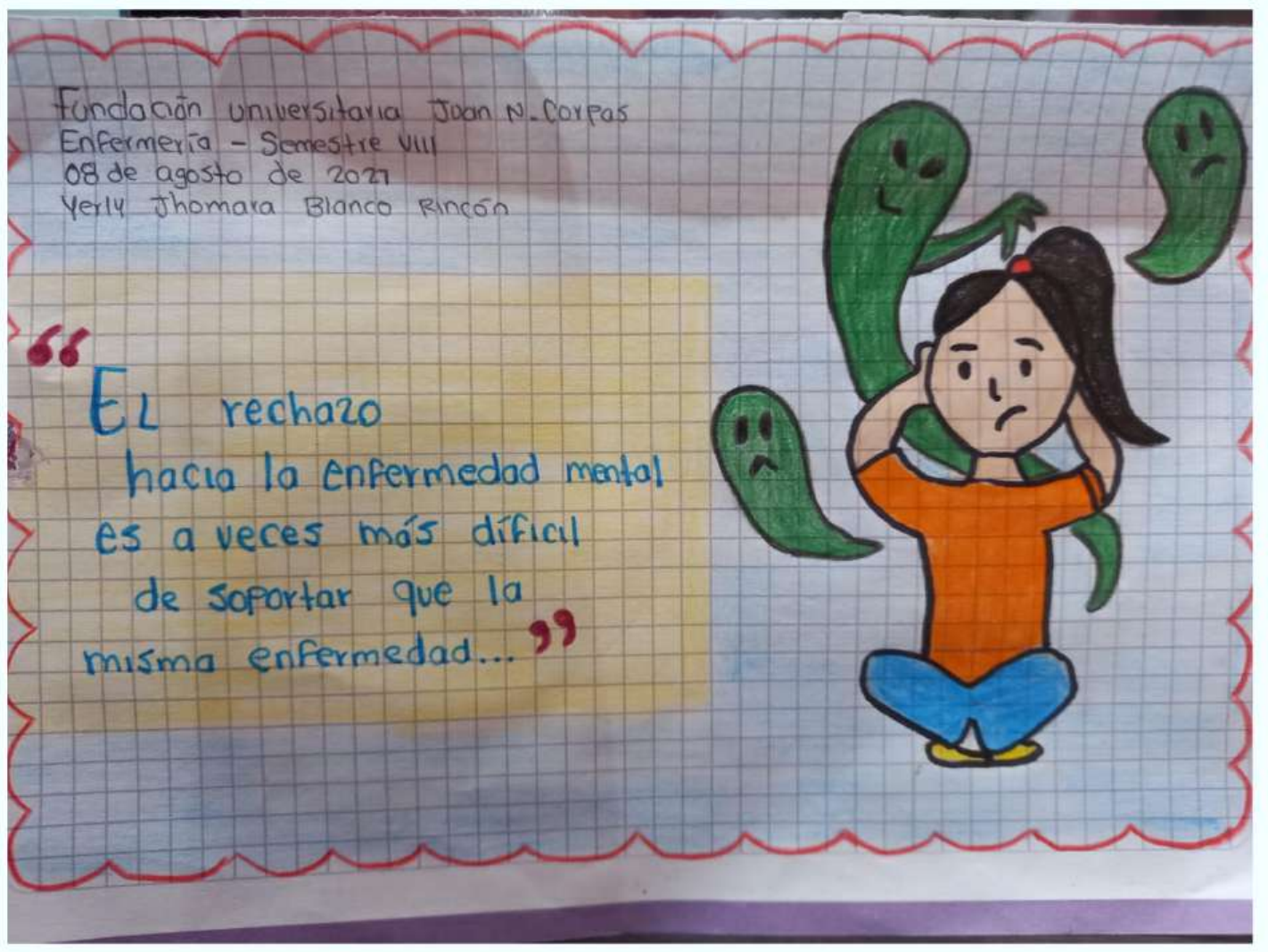




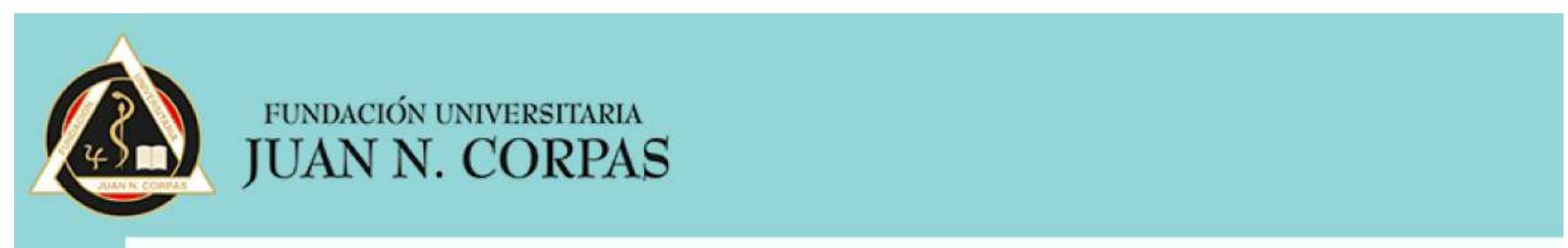

\section{HILANDO EL CAMBIO}

\section{BRANDON ESTEBAN BRICEÑO PIQUETERO}

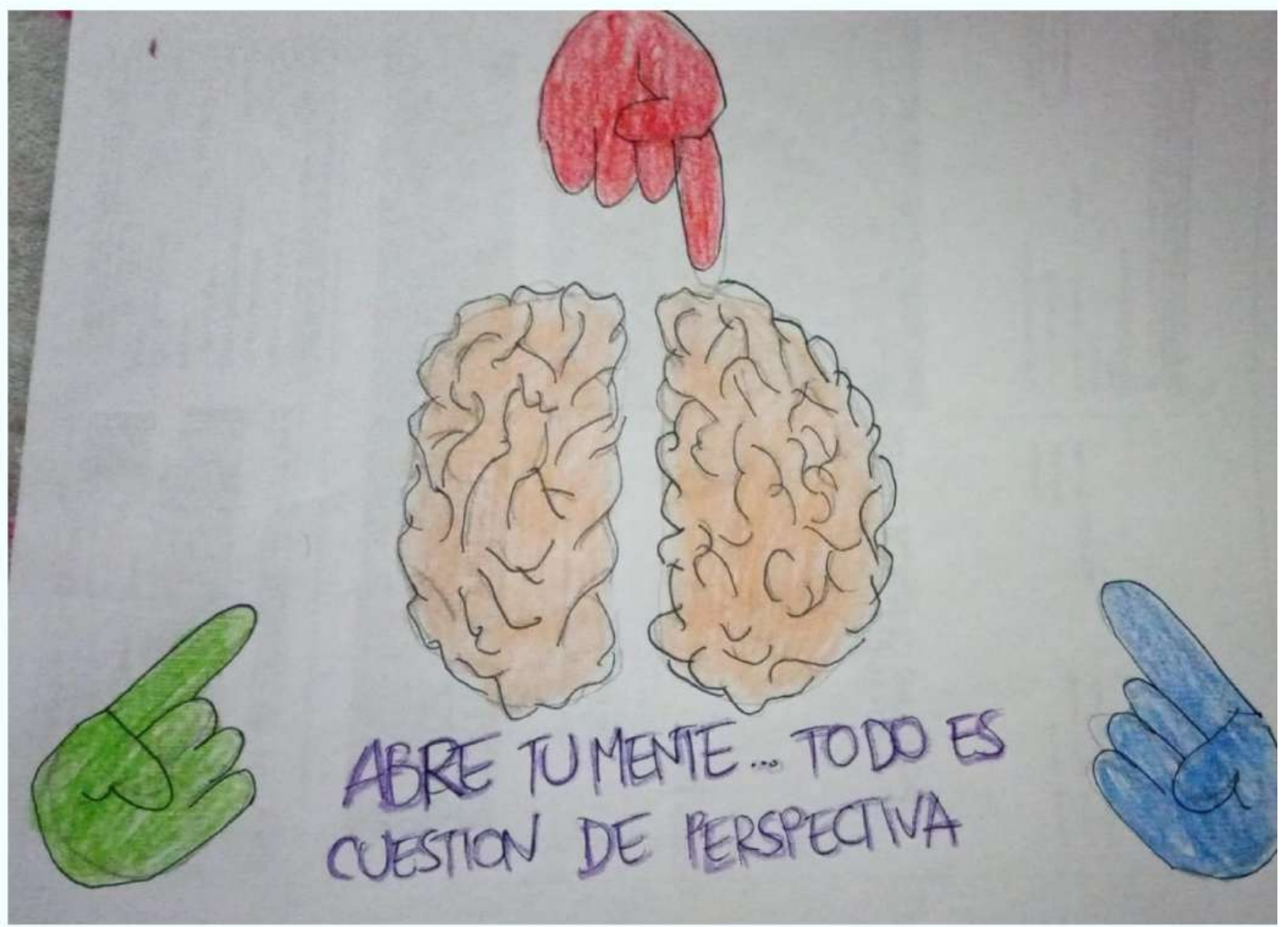




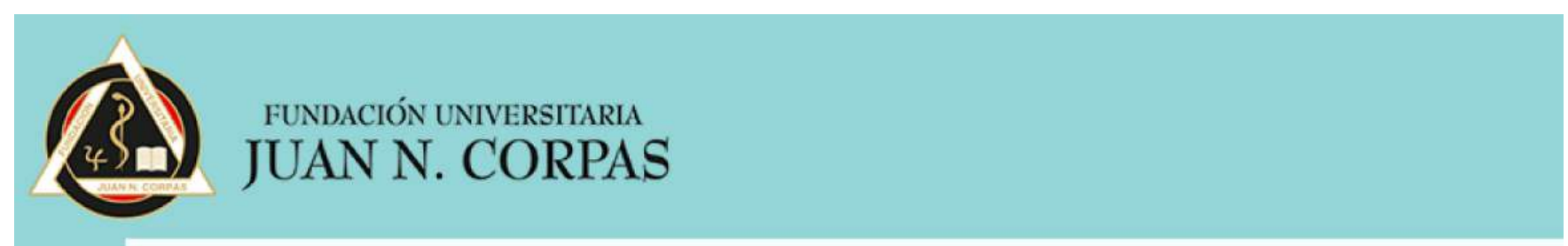

\section{HILANDO EL CAMBIO}

\section{LIZETH VANESSA CAMPOS CARDENAS}

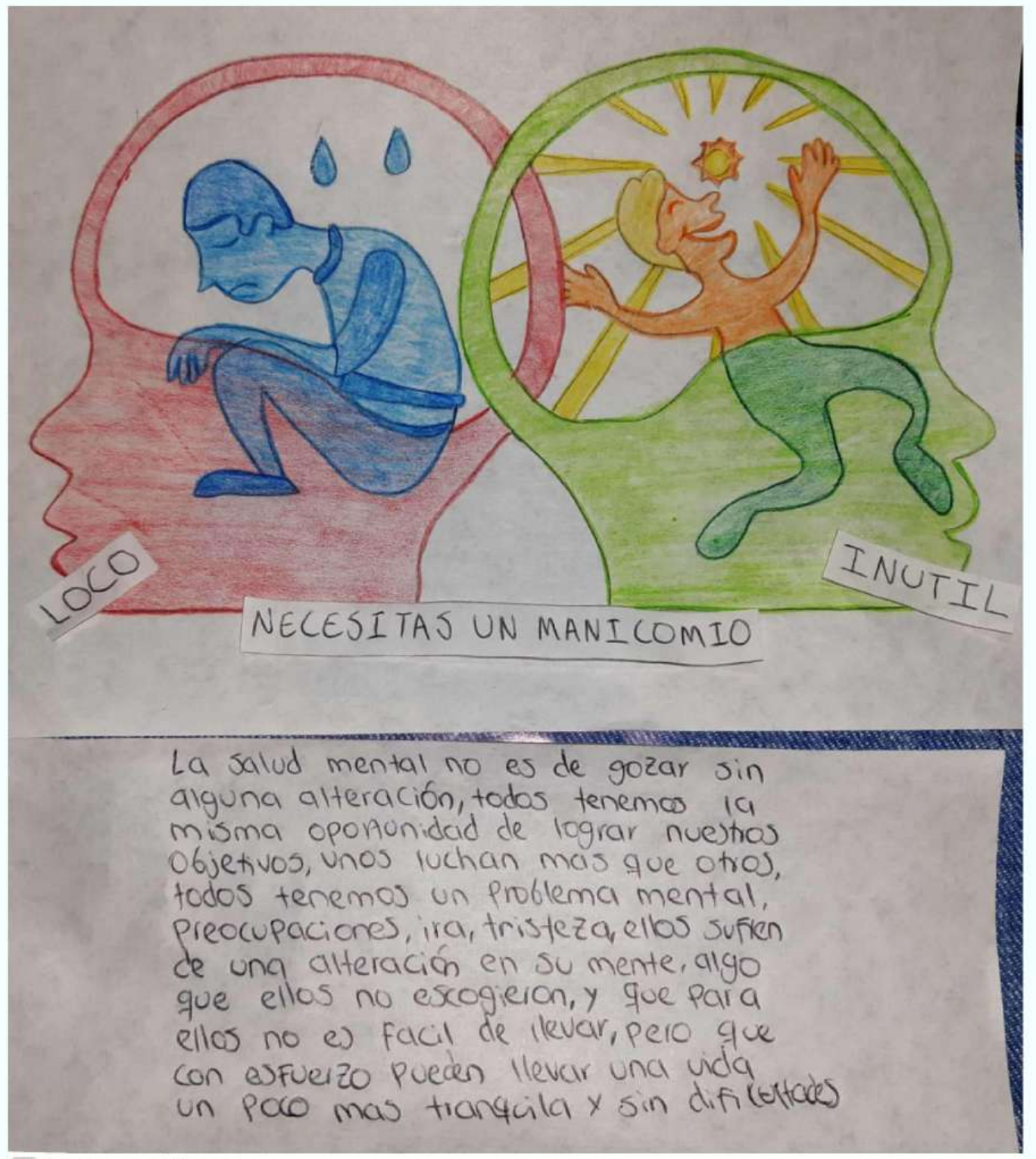




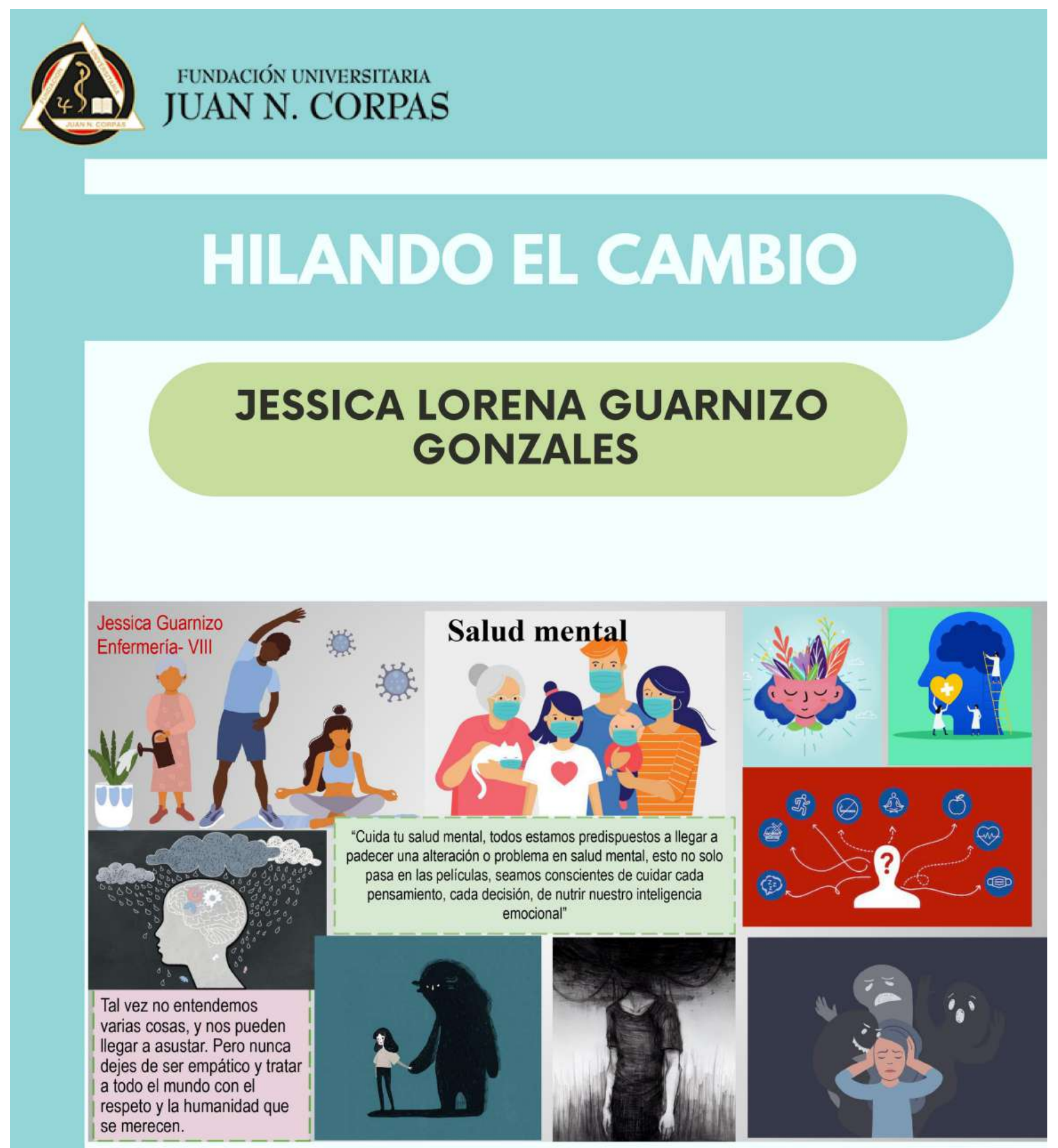




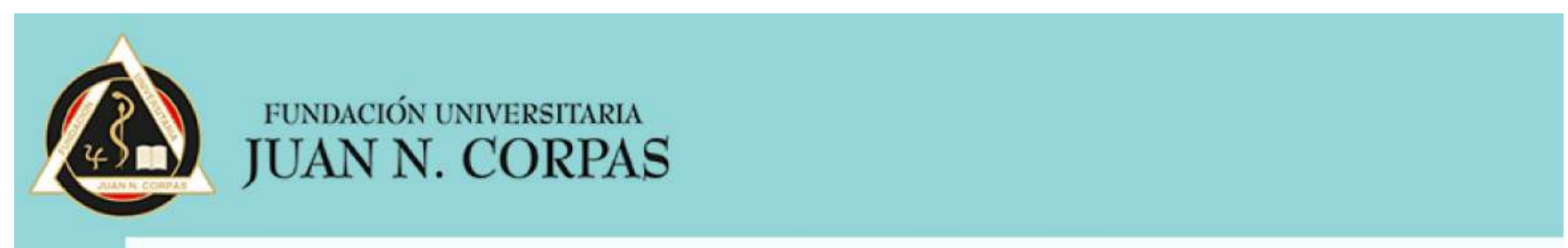

\section{HILANDO EL CAMBIO}

\section{CAMILA ANDREA LOZANO DIAZ}

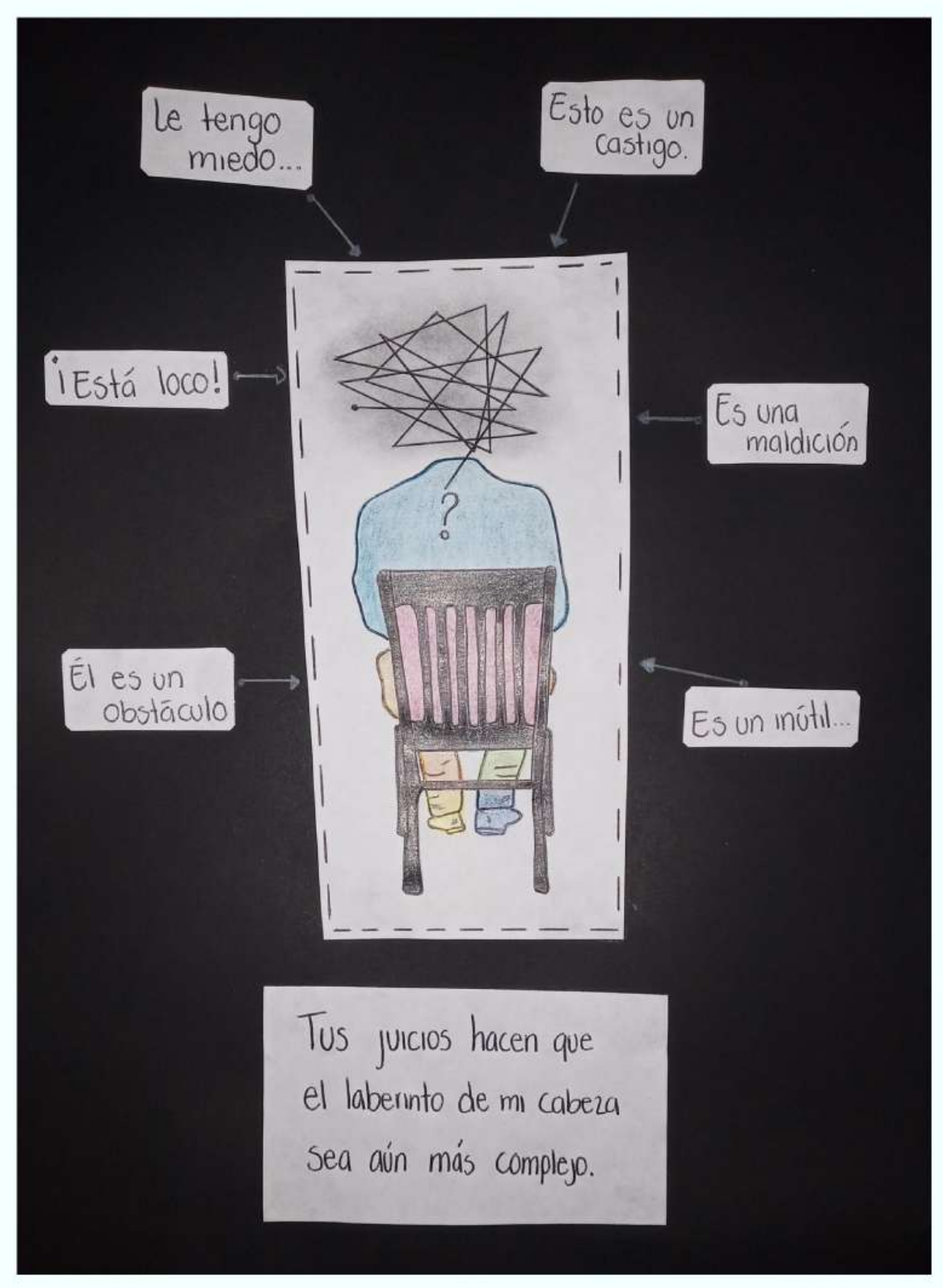




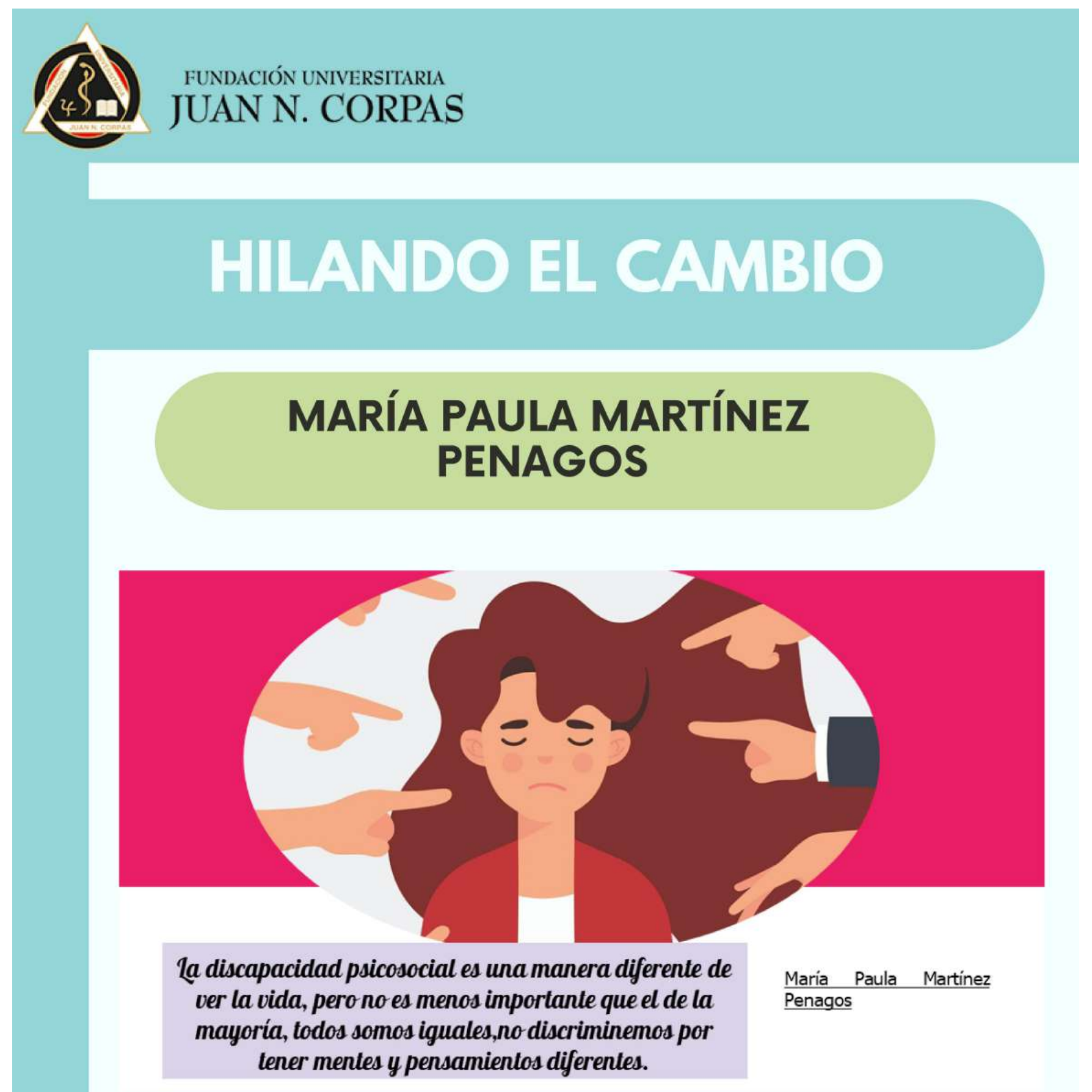




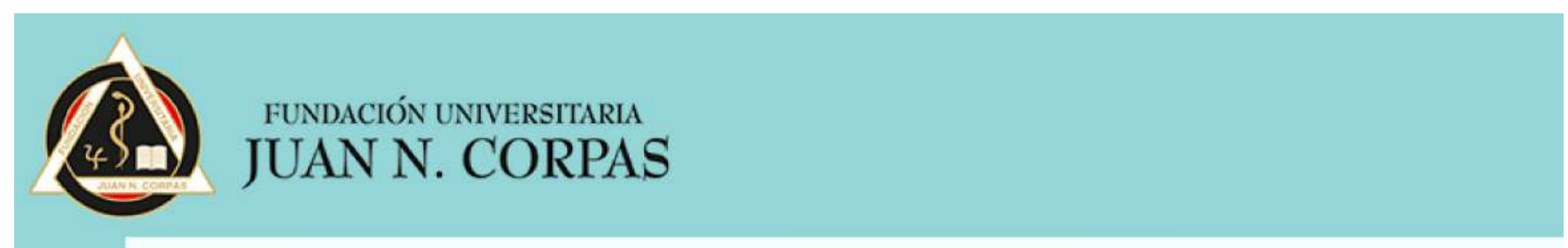

\section{HILANDO EL CAMBIO}

\section{KAREN ANDREA MORA JIMENEZ}

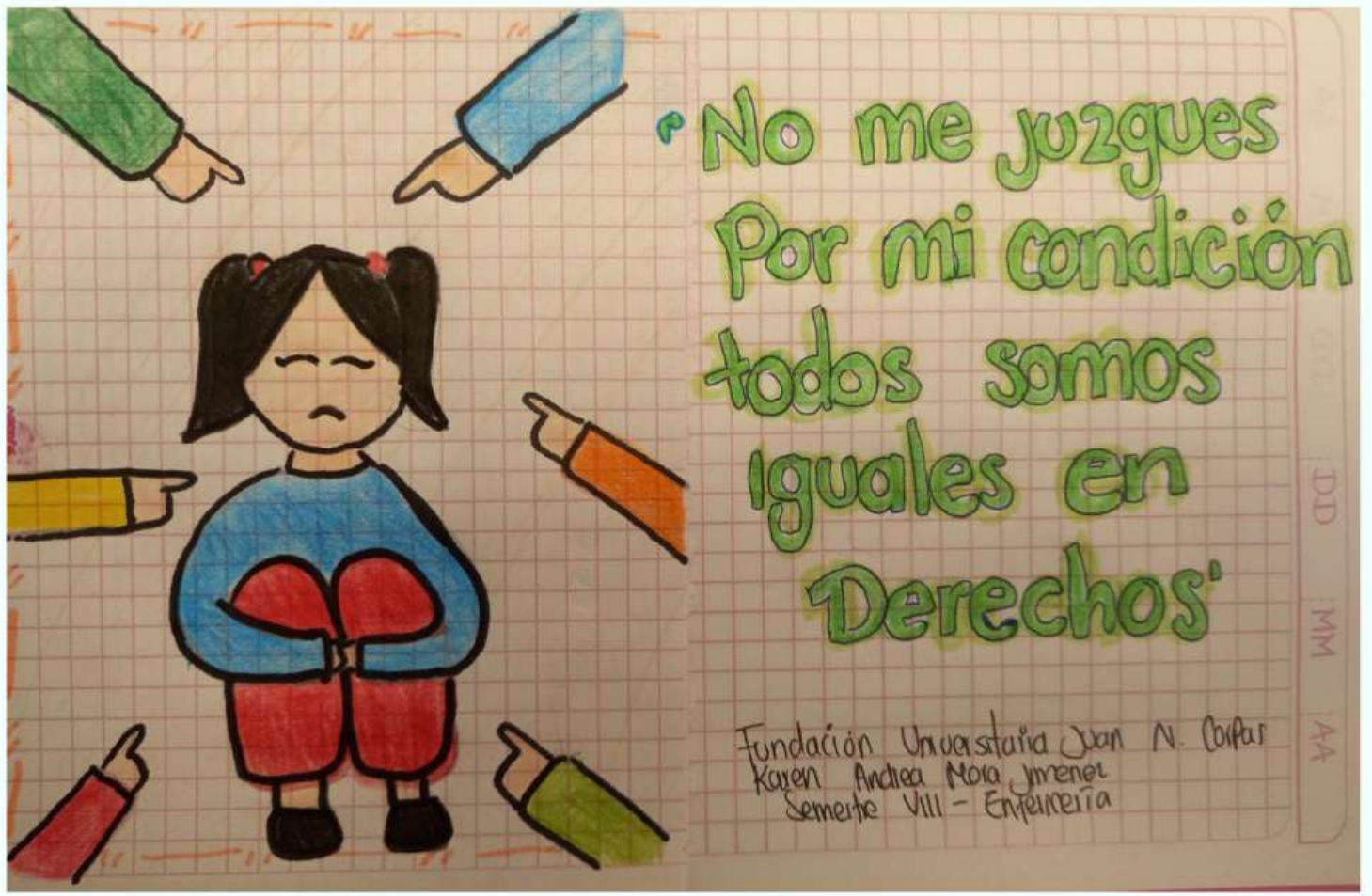




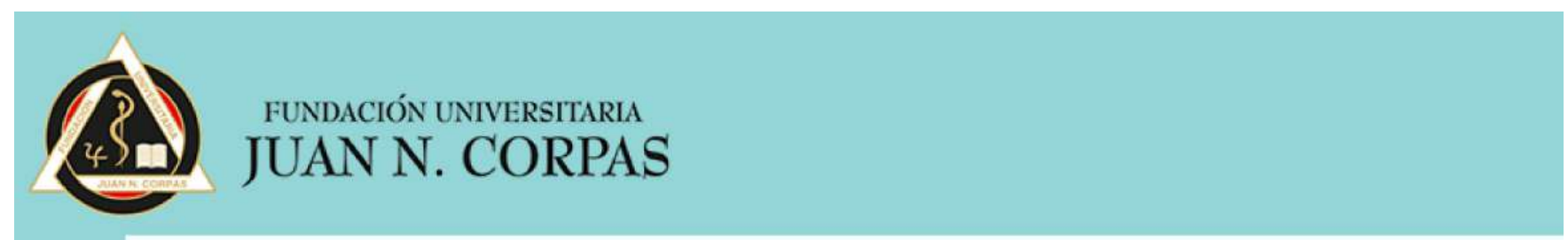

(D) (1)

\section{VALENTINA MORALES JIMENEZ}

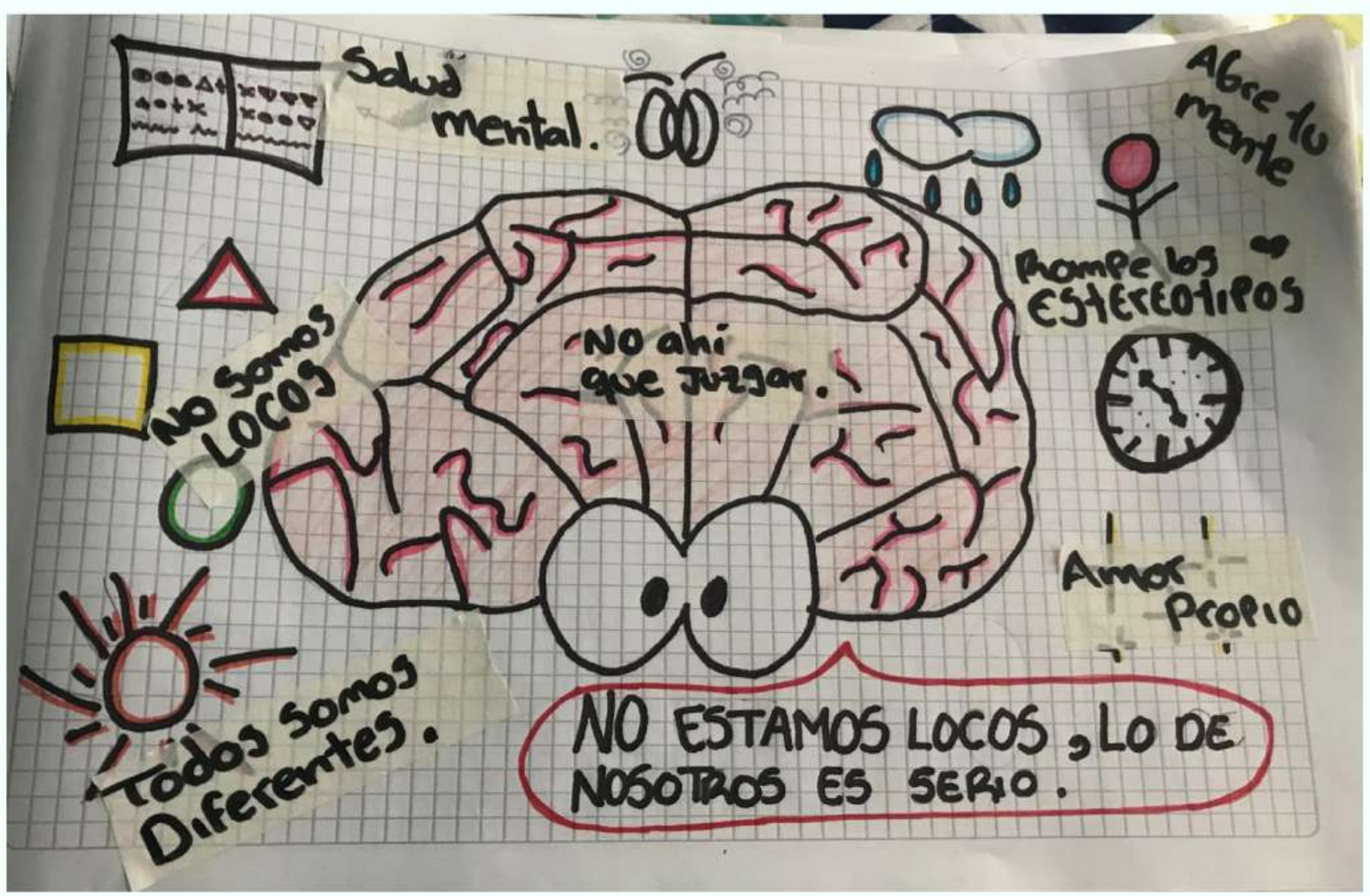




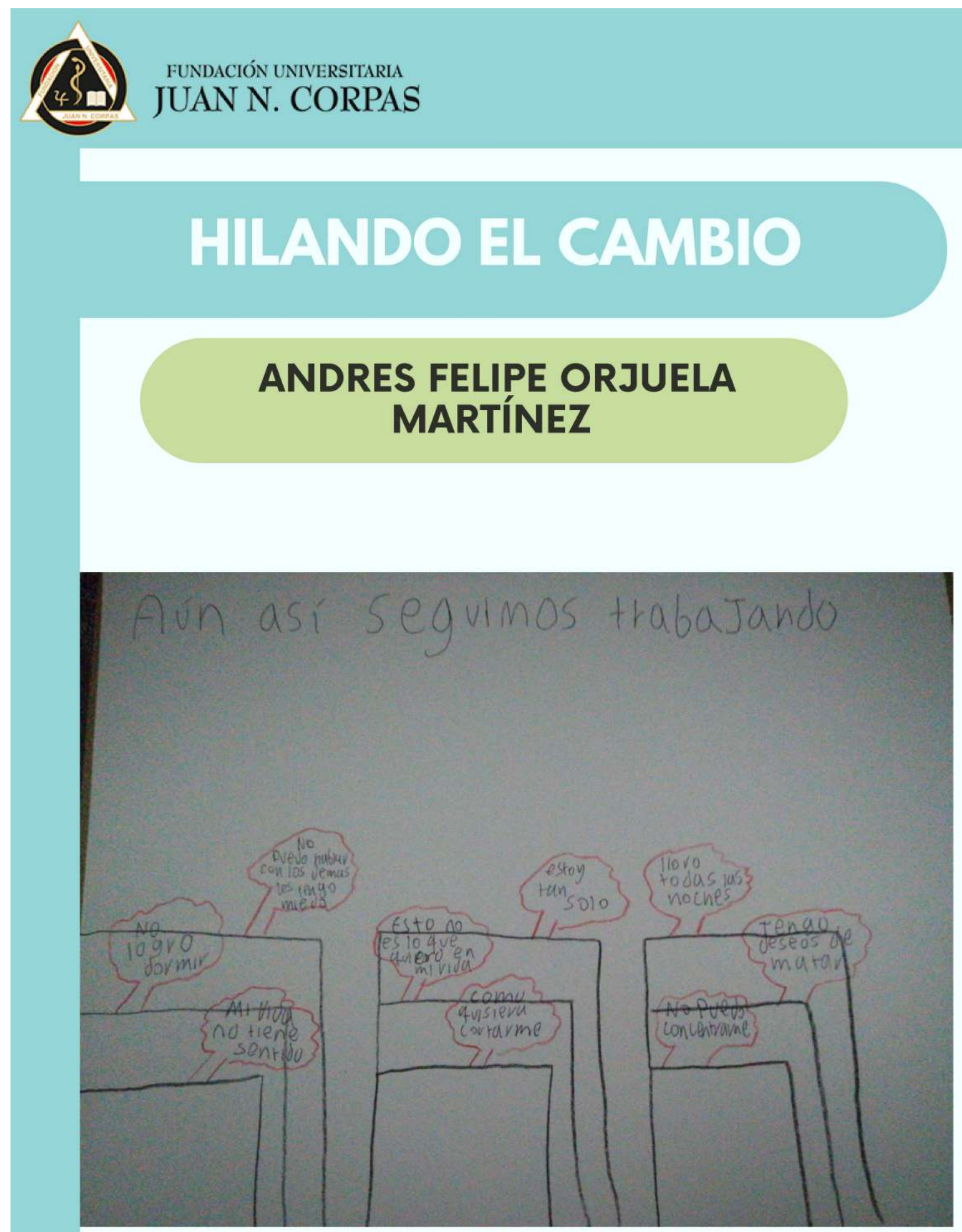




\section{HILANDO EL CAMBIO}

\section{ANA MARÍA PINZÓN FERNANDEZ}

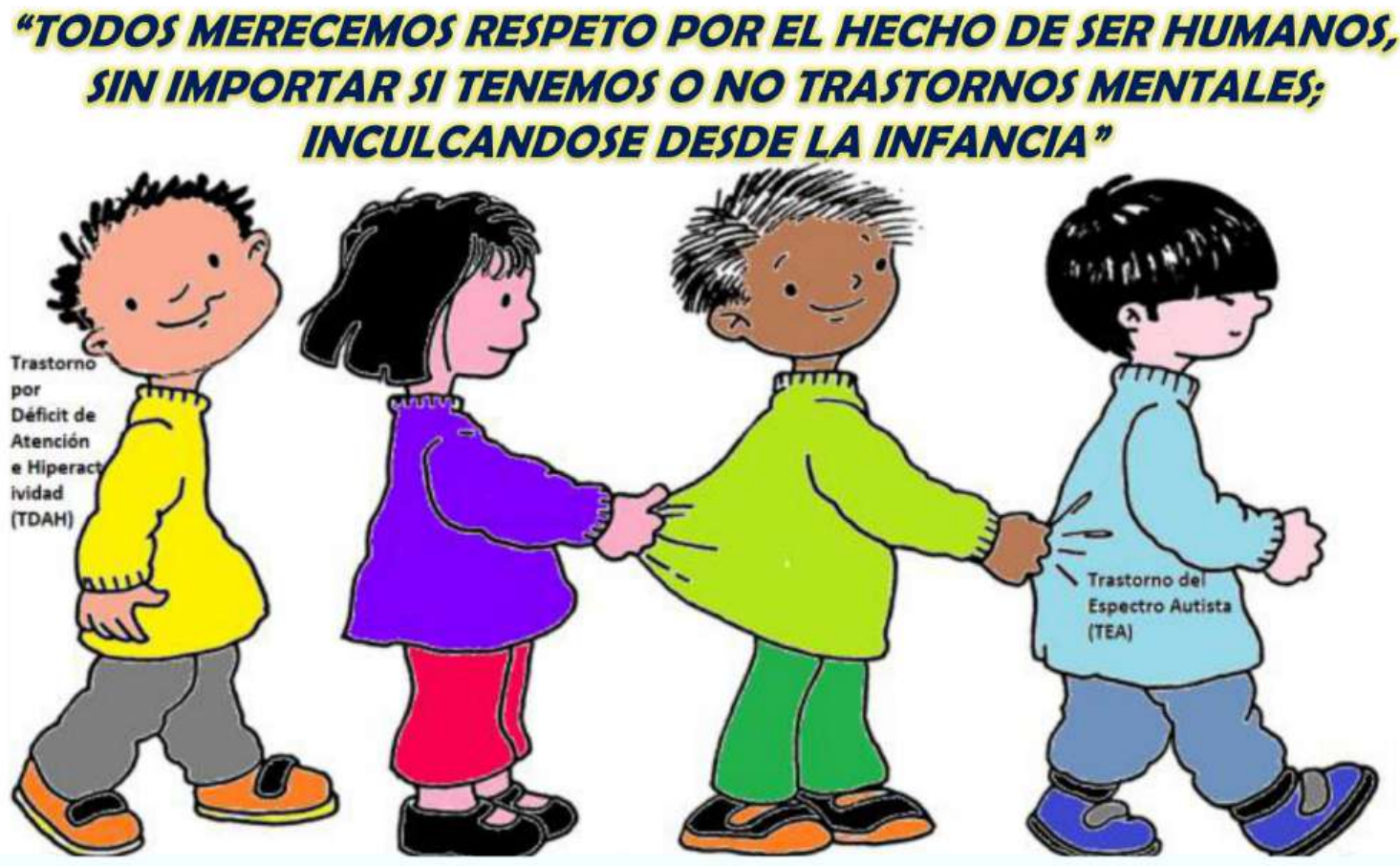




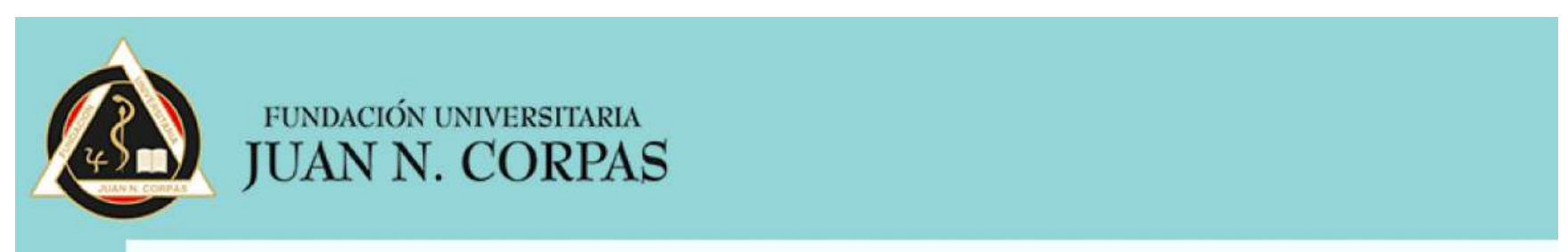

\section{HILANDO EL CAMBIO}

\section{LAURA CATALINA PIÑEROS LÓPEZ}

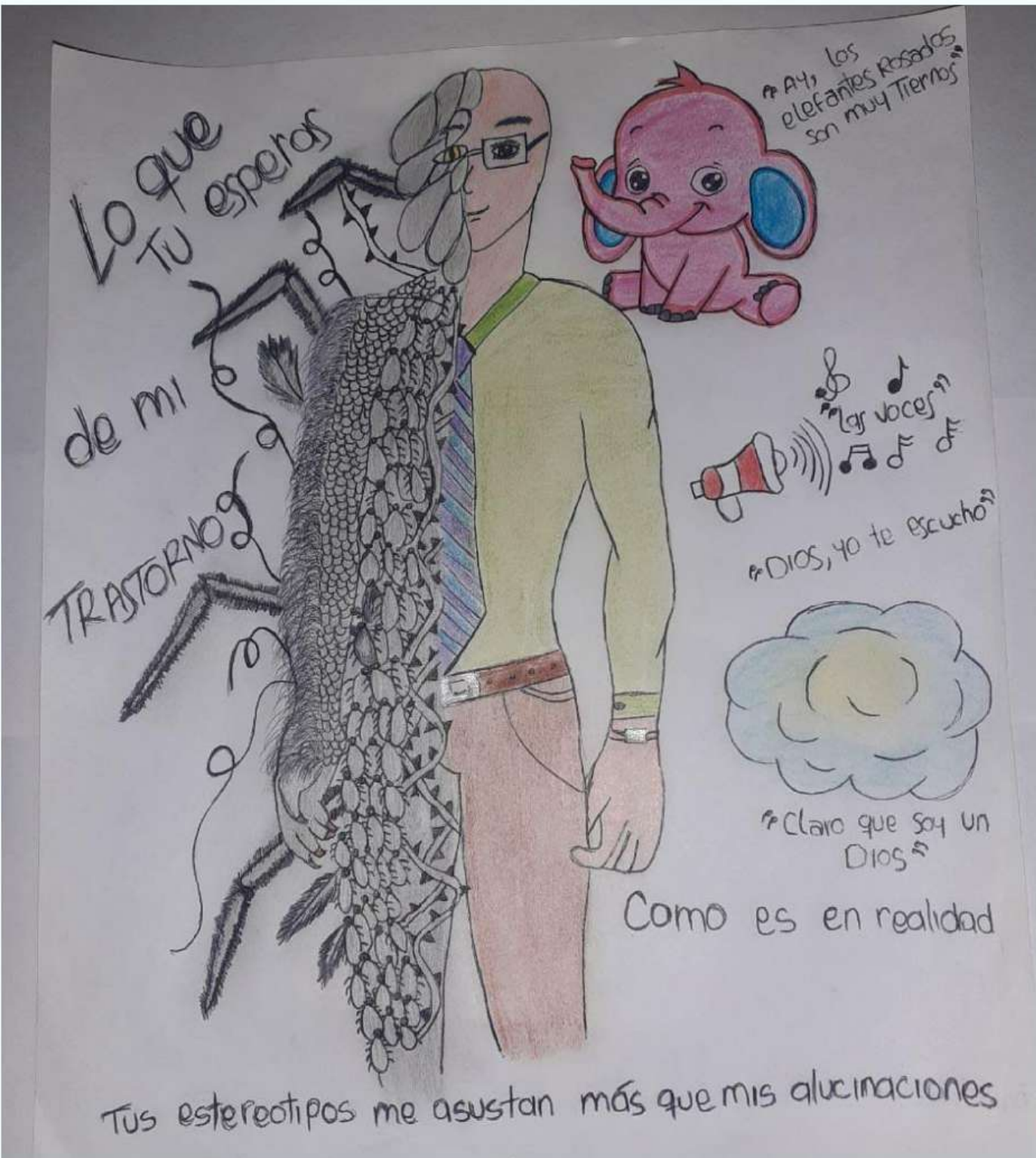




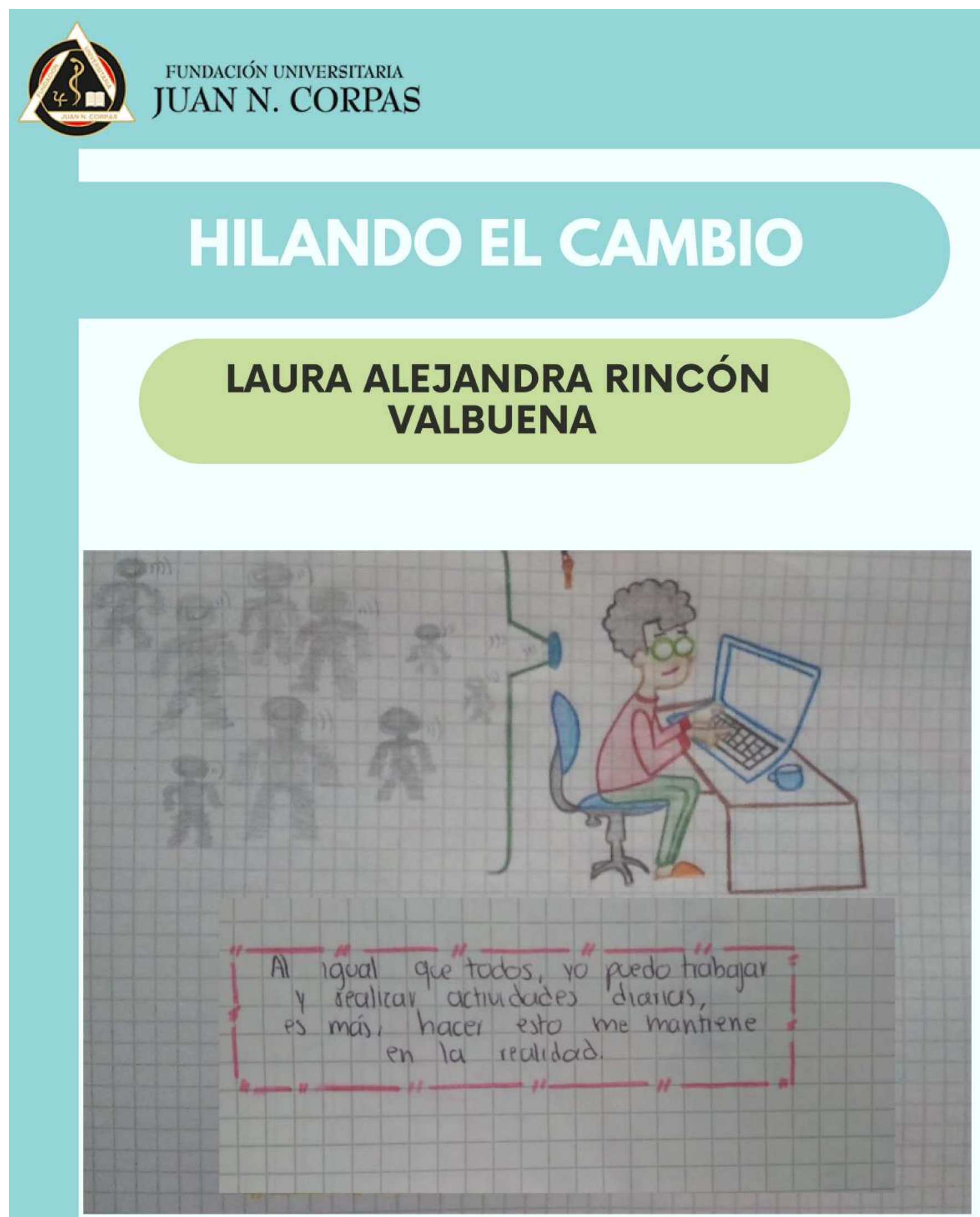




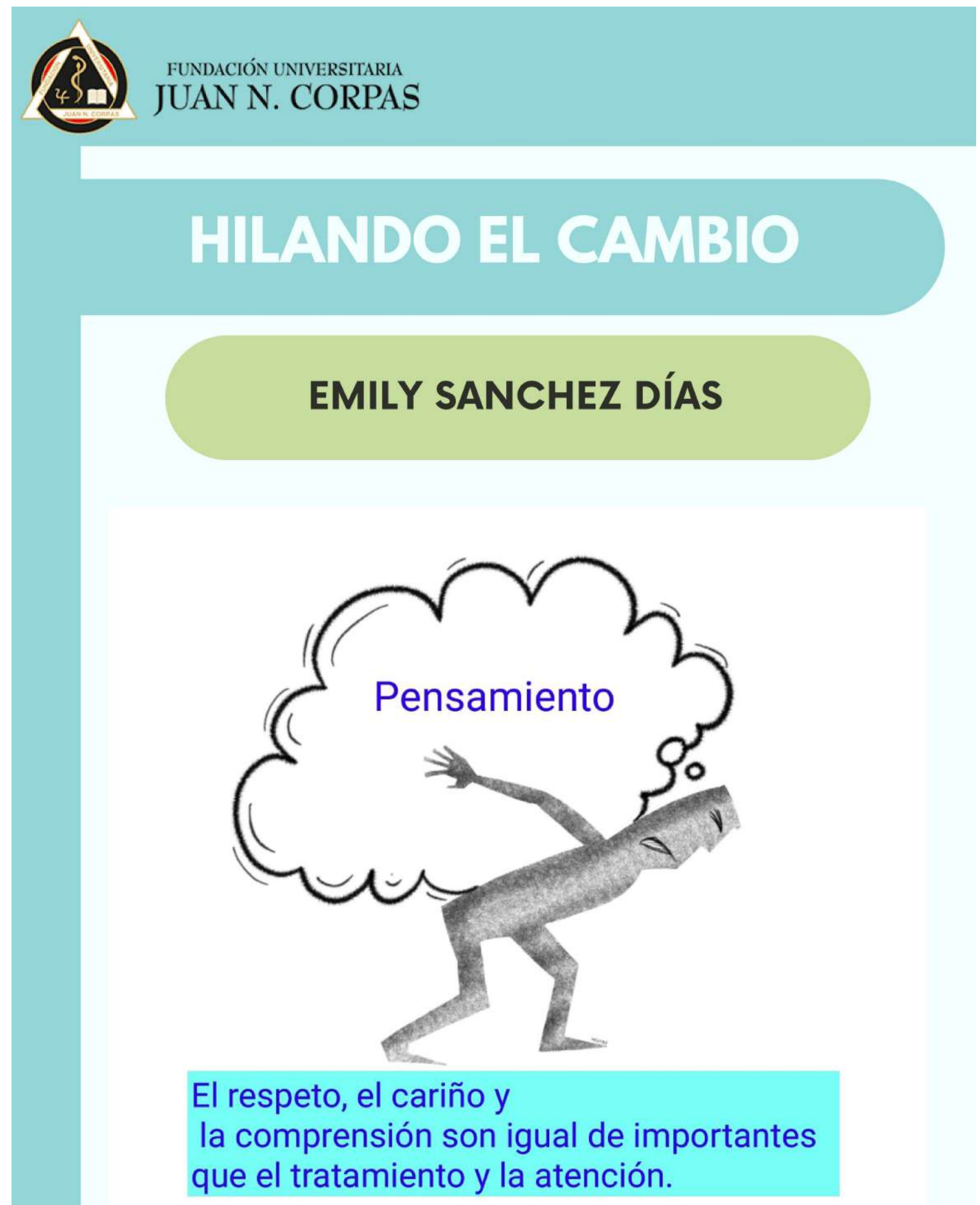




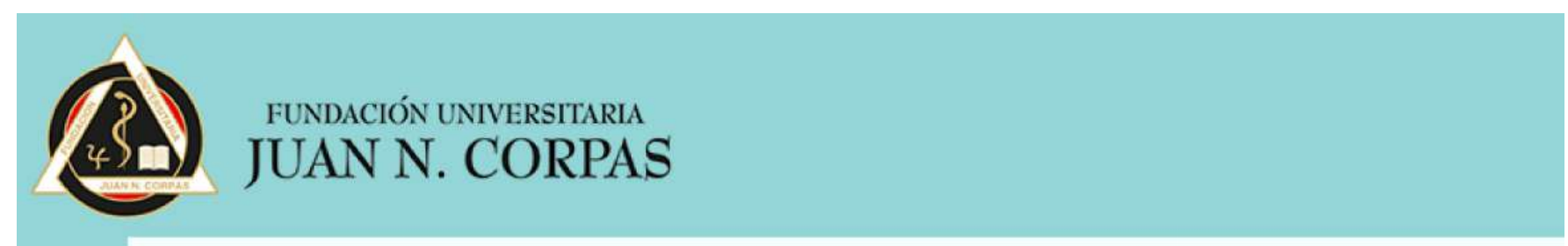

\section{HILANDO EL CAMBIO}

\section{LAURA KATHERINE SUAREZ SANDOBAL}

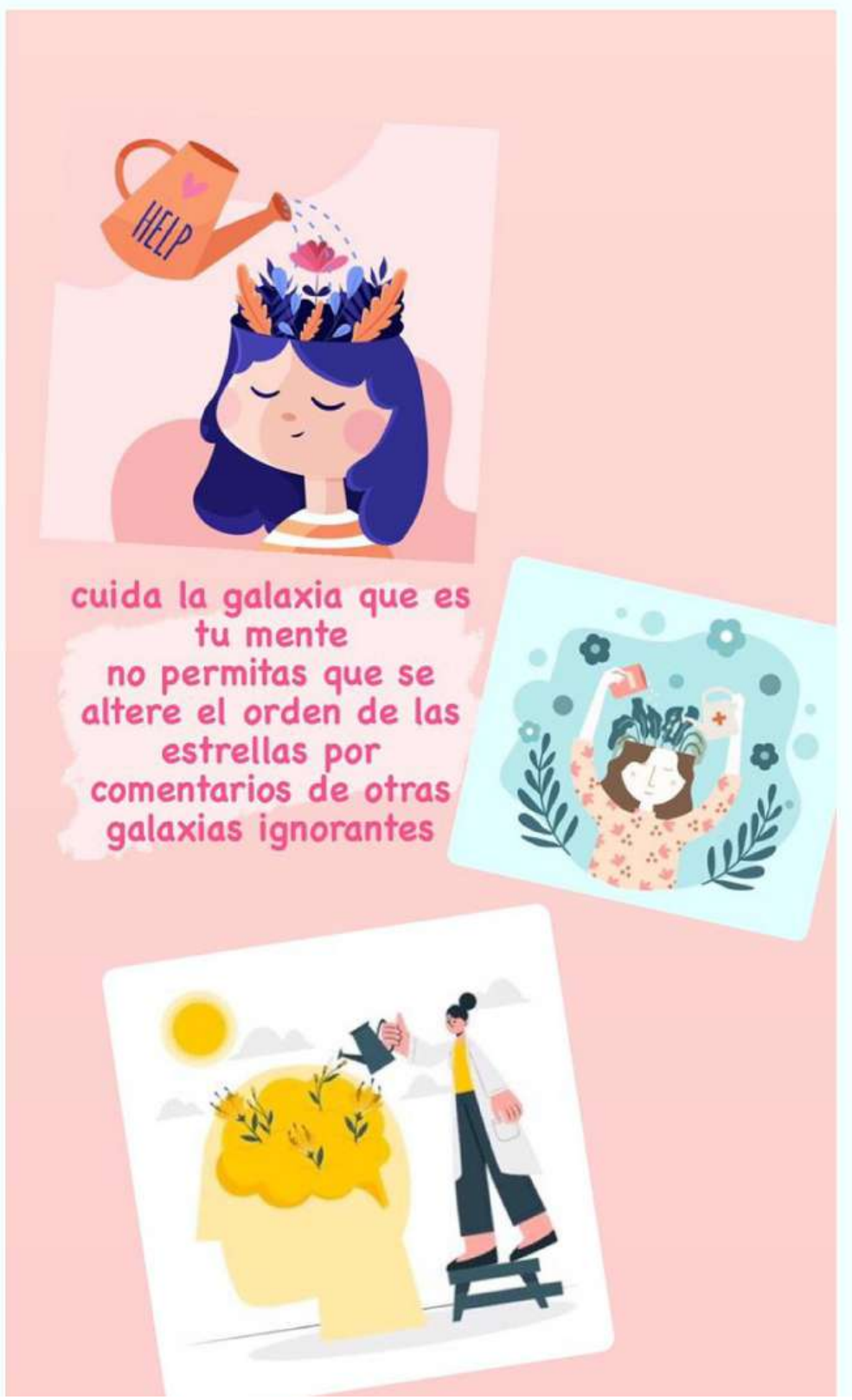




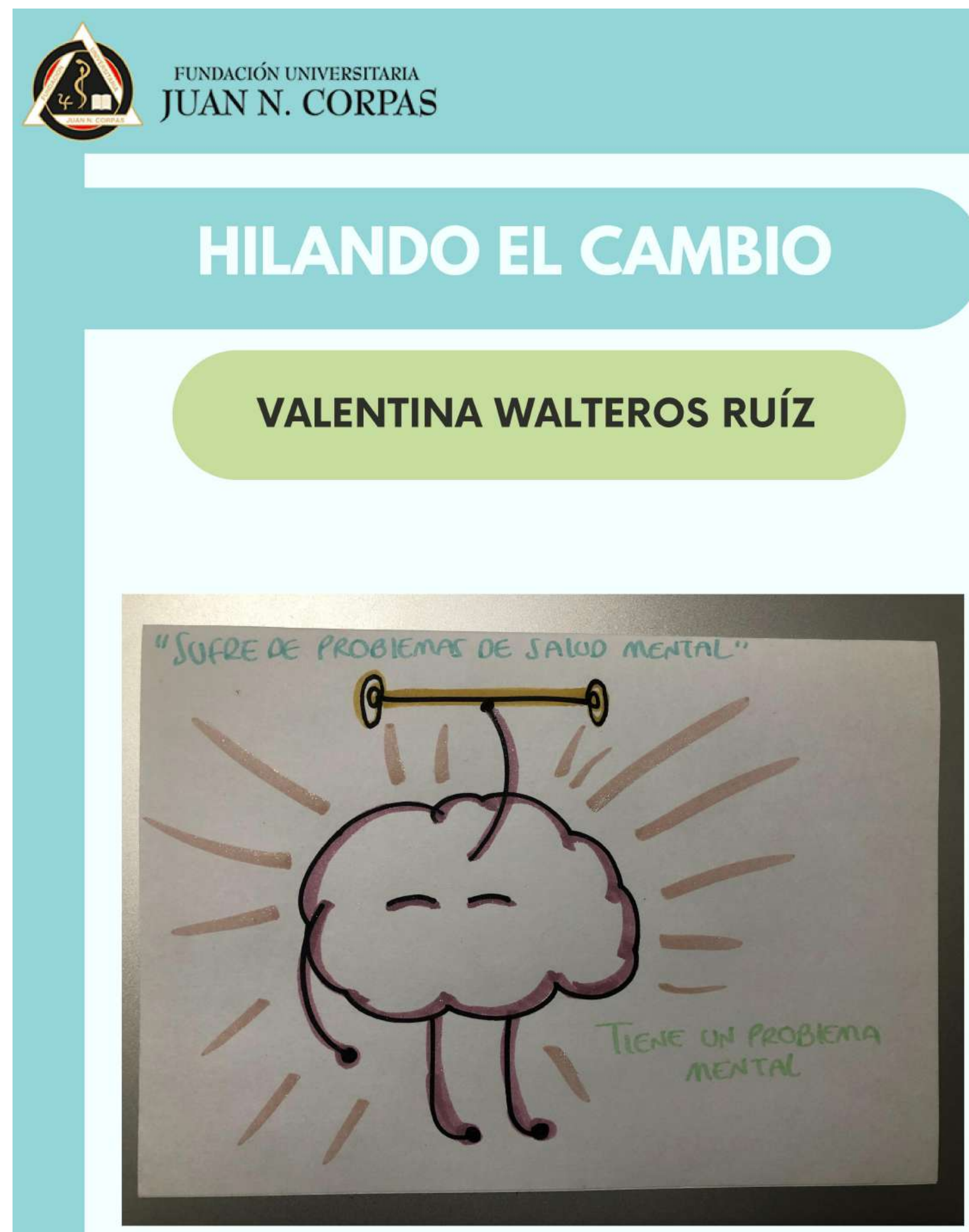




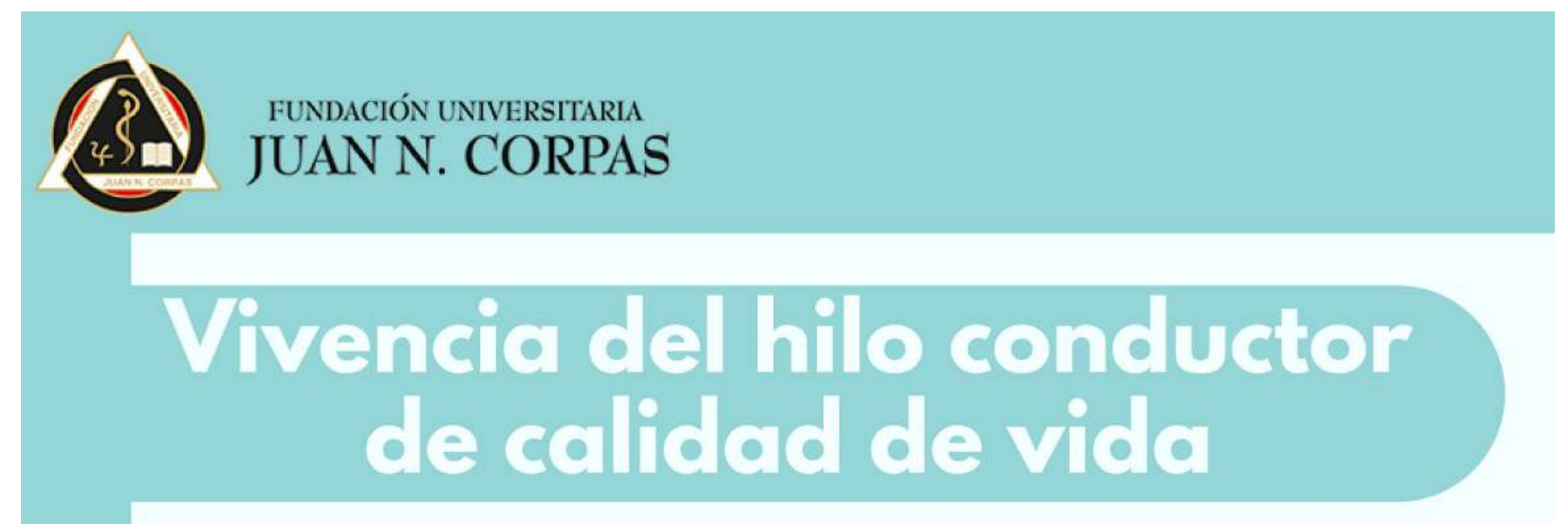

A lo largo de los 8 semestres, desarrollamos muchas habilidades que nos serán útiles en el ejercicio de la profesión, la mayoría de las materias se enfocaba en el cuidado y la protección de la persona, sin embargo, una de las materias que nos acompaño durante todo el recorrido del programa desde primer semestres hasta el último semestre, se enfoco en el cuidado de nosotros como personas, de crear herramientas y estrategias que nos protegerán de las situaciones complicadas de la profesión y sobre todo de cuidar nuestra salud mental. El hilo conductor de cuidado y calidad de vida significo muchas cosas tanto en el ámbito profesional como en el personal, a nivel personal hubo un crecimiento espiritual, un autoaprendizaje y una autocritica de las acciones que se realizan. El recorrido de la materia inicio contestando la pregunta tal vez más difícil de la carrera, ¿Quién soy yo? Esta pregunta me hizo replantear todo mi autoconcepto y llegar a treguas con muchos de mis conflictos internos. Luego de saber quién soy, seguía saber como me relacionaba con las personas de mi entorno y como creaba vínculos afectivos; desde esa perspectiva pude evidenciar la importancia de como reconocer las relaciones que tenían gran significado en mi vida. El cuestionarme constantemente de mis acciones, mi pensamiento, mis actitudes y mi forma de relacionarme con las personas me ayudo a generar un cambio interno que se vio reflejado no solo en mi rendimiento académico sino en mi desarrollo como enfermera y como miembro activo de la sociedad. En el ámbito profesional tuvo un gran impacto ya que me enseño a ver la persona como un todo, como un ser integro y no solo como un paciente con una dolencia o como una simple patología.

Laura Catalina Piñeros López

El conocimiento adquirido durante el hilo conductor de salud mental, me permitió tanto como estudiantes como persona aprender a conocer la mente, iniciando por la mía y proyectando ese conocimiento a los demás. El compartir con personas con trastornos mentales no solo me permite entenderlos más claramente, si no que nos muestra su humanidad escondida tras el miedo y el estigma escondido en su diagnóstico. Creo que todo profesional de la salud debería tener una aproximación tanto a su mente como a la de los demás.

Daniel Becerra Pabón 


\section{Vivencio del hilo conductor de calidad de vide}

El hilo conductor de Cuidado y Calidad de Vida se desarrolla de primer semestre a octavo. En la etapa de fundamentación, durante los tres primeros semestres, los estudiantes se acercan a su realidad interna, para reconocerse y encontrar rutas personales que fortalezcan la relación intrapersonal, la relación con otros y los lazos comunales y sociales. Durante los siguientes semestres, profundizan en aspectos que permiten el cuidado integral cuerpo-mente, lo que permite comprender, por curso de vida, los principales problemas que abordan las personas y los recursos que favorecerán prestar estos cuidados. En el último semestre, los estudiantes se encuentran con el trastorno mental, tanto en fase aguda como crónica, y comprenden los cuidados que promueven la salud mental en esta población tan aquejada por sus síntomas y por aspectos sociales y culturales como el estigma que es el objeto del presente trabajo.

Maritza Barroso Niño

Docente

Coordinadora del hilo conductor de Cuidado y Calidad de Vida

(C) 2021 Fundación Universitaria Juan N. Corpas (FUJNC).

Articulo Open Access bajo la Licencia Creative Commons Atribución-

NoComercial-Compartir Igual 4.0 Internacional.

DOI: https://doi.org/10.26752/revistaparadigmassh.v3iSupl.1.612 